\title{
BMJ Open Prevalence and associated factors of skin diseases in aged nursing home residents: a multicentre prevalence study
}

\author{
Elisabeth Hahnel, Ulrike Blume-Peytavi, Carina Trojahn, Gabor Dobos, \\ Irina Jahnke, Vera Kanti, Claudia Richter, Andrea Lichterfeld-Kottner, \\ Natalie Garcia Bartels, Jan Kottner
}

To cite: Hahnel E, BlumePeytavi U, Trojahn C, et al. Prevalence and associated factors of skin diseases in aged nursing home residents: a multicentre prevalence study. BMJ Open 2017;7:e018283. doi:10.1136/ bmjopen-2017-018283

- Prepublication history and additional material for this paper are available online. To view these files, please visit the journal online (http://dx.doi. org/10.1136/bmjopen-2017018283).

Received 22 June 2017 Accepted 23 August 2017

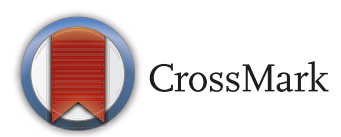

Charité-Universitätsmedizin Berlin, Department of Dermatology and Allergy, Clinical Research Center for Hair and Skin Science, Berlin, Germany

Correspondence to

Elisabeth Hahnel;

elisabeth.hahnel@charite.de

\section{ABSTRACT}

Objectives The aim of this study was to measure the prevalence of skin diseases in aged nursing home residents and to explore possible associations with demographic and medical characteristics.

Design Descriptive multicentre prevalence study. Setting and participants The study was conducted in a random sample of ten institutional long-term care facilities in the federal state of Berlin, Germany. In total, $n=223$ residents were included.

Results In total, 60 dermatological diseases were diagnosed. The most frequently diagnosed skin disease was xerosis cutis $(99.1 \%, 95 \% \mathrm{Cl} 97.7 \%$ to $100.0 \%)$ followed by tinea ungium $(62.3 \%, 95 \% \mathrm{Cl} 56.0 \%$ to $69.1 \%)$ and seborrheic keratosis $(56.5 \%, 95 \% \mathrm{Cl} 50.2 \%$ to $63.0 \%)$ Only few bivariate associations have been detected between skin diseases and demographic and medical characteristics.

Conclusion Study results indicate that almost every resident living in residential care has at least one dermatological diagnosis. Dermatological findings range from highly prevalent xerosis and cutaneous infection up to skin cancer. Not all conditions require immediate dermatological treatment and can be managed by targeted skin care interventions. Caregivers need knowledge and diagnostic skills to make appropriate clinical decisions. It is unlikely that specialised dermatological care will be delivered widely in the growing long-term care sector. Trial registration number This study is registered at https://clinicaltrials.gov/ct2/show/NCT02216526.

\section{INTRODUCTION}

\section{Background}

Skin ageing, functional limitations, chronic diseases, polypharmacy, personal skin care and hygiene habits in populations aged $\geq 65$ years cause an increased vulnerability to skin diseases and cutaneous problems. ${ }^{1-3}$ Epidemiological studies suggest that skin diseases are highly prevalent in the elderly population. ${ }^{4-6}$ For example, the prevalence of xerosis cutis range up to $85.5 \%$, benign skin tumours up to $74.5 \%$, fungal infections up to $77 \%$ and
Strengths and limitations of this study

- This was the largest randomly selected sample of long-term care residents aged $\geq 65$ years undergoing a head-to-toe skin examination by board certified dermatologists.

- Skin diseases, medications and concomitant diseases were classified according to international definitions and functional assessments were conducted according to established methods to support the generalisability of results.

- Although three additional institutional long-term care facilities were included, the anticipated sample size of $n=280$ was not achieved.

- There were differences between participating and non-participating long-term care institutions.

- Systemic diseases were not specified and laboratory and histology data were not available.

pressure ulcer (PU) up to $46 \% .^{78}$ However, most published epidemiological figures were obtained in hospital settings. The epidemiology of cutaneous diseases in institutional long-term care settings is largely unknown, ${ }^{7}$ although the number of multimorbid residents living in institutional long-term care is increasing. ${ }^{9}$

In addition to the high prevalence, the burden of skin diseases also increases with age. ${ }^{6}$ They are associated with reduced quality of life. ${ }^{10}$ It was shown that geriatric patients with dermatological diseases have an increased risk for mental and behavioural disorders, primarily depression. ${ }^{11}$ The medical treatment of the mulitmorbidities in nursing home residents may also result in polypharmacy. ${ }^{12}$ Associated adverse drug reactions, non-adherence or drug-drug interactions are common $^{1314}$ and linked to dermatological disorders. Immobility, cognitive impairment and organisational or reimbursement factors 
may also limit the opportunity for these population to receive specialised dermatological care. Traditionally, nurses and other healthcare professionals focus on PUs and incontinence-associated dermatitis (IAD) but may ignore other skin problems which may also require attention. On the other hand, not all dermatological conditions require specialised pharmacological treatment.

According to the latest statistics, there are 800.000 residents living in 13.600 long-term care institutions in Germany ${ }^{15}$ and these figures are expected to increase. At the same time, the prevalence of skin diseases in this care setting is largely unknown. In order to gain a detailed picture about the epidemiology of skin diseases in institutional long-term care this study was conducted.

\section{Objectives}

The aim of this study was to measure the prevalence of skin conditions and diseases in aged residents living in institutional long-term care facilities and to explore possible associations with demographic and medical characteristics.

\section{MATERIALS AND METHODS \\ Study design}

This was an observational, cross-sectional prevalence study and it was approved by the ethics committee of the Charité-Universitätsmedizin Berlin (EA1/190/14). The study protocol was published previously. ${ }^{16}$

\section{Setting}

The study was conducted from September 2014 to May 2015 in 10 institutional long-term care facilities in Berlin, Germany. In Germany, institutional long-term care facilities or residential care facilities are full-time accommodations with professional care. The staff is a mix between registered nurses and nursing assistants. Using computer-generated random numbers, institutional long-term care facilities from a list of all existing facilities $(n=291)$ in the federal state of Berlin, Germany were contacted. In case of non-response, the next randomly selected nursing home was invited.

\section{Participants}

The inclusion criteria were (1) being resident of the respective residential care facility, (2) aged $\geq 65$ years, and (3) written informed consent given personally or by legal representative. Only residents being able to give informed consent by themselves or having a legal representative who decided on behalf of the resident took part in this study. The exclusion criterion was residents at the end of life to avoid unnecessary burden due to the examinations. All residents (or their legal representatives) living in the residential care facility at time of data collection were invited to participate.

\section{Variables}

Skin diseases were classified according to the International Coding of Diseases (ICD-10) classification, with the exception of IAD and skin tears. IAD was diagnosed according to the IAD-IT classification of Junkin 2008. ${ }^{17}$ According to an international consensus, skin tears are caused by shear, friction and/or blunt force causing the separation of the layers of the skin (partial or full thickness wound) most commonly on the extremities. ${ }^{18}$ Skin tears were recorded as present/absent. Xerosis cutis was measured using the Overall Dry Skin score (ODS) with a 5-point scale ranging from ' 0 ' (no skin dryness) to ' 4 ' (advanced skin roughness, large scales, inflammation and cracks). ${ }^{19}{ }^{20}$ Concomitant diseases (ICD-10 classification level 1) and medications were extracted from the medical records. These contain documentation of anamnesis, diagnoses, examination results, therapies and results, interventions and medical letters. Demographic variables of the nursing home residents (eg, age and sex) were collected. The physical function related to the daily activities was assessed using the Barthel Index. The scores range from 0 (very care dependent) to 100 (not care dependent). ${ }^{21}$ The Braden scale was used to measure PU risk. Scores range from 6 (high PU risk) to 23 (no PU risk). ${ }^{22}$ The educational qualification was classified into the following six categories: 'no school qualification', 'primary school', 'secondary school', 'grammar school/Alevel', 'vocational training' and 'university qualification'.

\section{Data sources and measurement}

All participating nursing home residents underwent a head-to-toe skin examination conducted by a board certified dermatologist (UBP, NGB, IJ). Examinations were done by clinical evaluation and using dermatoscopes (Dermogenius basic, DermoScan GmbH, Germany). Demographic characteristics (eg, age and sex) and information regarding school qualification were extracted from the medical records by trained study assistants or the residents were interviewed, if possible. PU risk and care dependency (Braden scale and Barthel Index) were extracted from the medical records or assessed by a registered nurse. All study data were continuously documented in data collection forms by the investigator and authorised staff.

\section{Bias}

Institutional long-term care facilities in the state of Berlin differ in terms of ownership, size, and specialisation. In order to reduce selection bias, institutions were randomly selected from all facilities of the state of Berlin. All study-related procedures and measurements were conducted by trained dermatologists and study assistants according to standard operating procedures. The board certified dermatologists had no access to medical history data of the residents prior and during examinations to reduce the risk of detection bias.

\section{Study size}

Assuming a prevalence of 0.5 of skin diseases, approximately 280 residents would have been needed to measure this proportion with a desired width of a $95 \%$ CI of \pm 0.06 . 
According to the latest Nursing Care Statistics (2013), the size of the long-term care population in Berlin was approximately $30.000 .{ }^{23}$ Assuming 80 residents per institution and a participation rate of $50 \%(\mathrm{n}=40)$, it was planned to include seven institutions which results in $\mathrm{n}=280(7 \times \mathrm{n}=40)$ cases.

\section{Quantitative variables}

The duration of residency was measured in months. The Barthel Index and Braden scale scores were used as metric variables. In order to investigate possible associations with skin diseases, the variable 'educational qualification' was dichotomized into 'university qualification' (yes/no). Residents taking four or more medications were regarded as having 'polypharmacy'. ${ }^{12}$

\section{Statistical methods}

Depending on the level of measurement (nominal, ordinal and continuous), demographic characteristics, functional assessment scores and dermatological diseases were described using means, medians, proportions, frequencies and associated spread estimates, standard deviations, ranges and interquartile ranges. The $95 \%$ CIs were calculated around point estimates of dermatological diseases. Exploratory data analysis to investigate possible bivariate associations were conducted using logistic regression analysis for all skin diseases with a prevalence of at least $8 \% .95 \%$ CIs of the ORs excluding 1 were considered to be statistically significant. ORs being statistically significant or with values lower than 0.5 or higher than2.0 were considered to be likely associated. In case of multiple bivariate associations, multivariable logistic regression analyses were conducted. Models were built iteratively to increase model fit indicated by Nagelkerke's $R^{2}$.

\section{RESULTS}

\section{Participants}

Fifty-five long-term care facilities were contacted. Finally, 10 long-term care facilities agreed to participate. Compared with participating institutions, non-participating institutions were larger in terms of number of beds (mean beds per institution: 104.5 vs 73.7 ) privately owned ( $76 \%$ vs $60 \%)$ and non-profit ( $30 \%$ vs $22 \%)$.

All residents of the eligible long-term care facilities were invited, but participation rate was $<50 \%$. In order to achieve the planned number, three additional longterm care facilities were recruited (in total 10). In total, $\mathrm{n}=811$ long-term care residents were assessed for eligibility, $\mathrm{n}=58$ residents $(23 \%)$ provided written informed consent by themselves and for $\mathrm{n}=194$ residents $(77 \%)$, the legal representative gave consent for participation. In total, $n=29$ residents declined participation prior examination resulting in $\mathrm{n}=223$ included long-term care residents (figure 1).

\section{Descriptive data}

Sample characteristics are shown in table 1. Most residents were women $(67.7 \%)$ and the mean age was 83.6
(SD 8.0) years. Mean Barthel Index score was 45.1 (SD 23.8) and mean Braden scale score was 17.3 (SD 3.7). The median time of long-term care residence until data collection was 27 months. A vocational training was the highest educational level for the majority $(48.9 \%)$. The most common concomitant diseases (ICD-10 system level 1) were diseases of the circulatory system $(82.5 \%)$ and mental and behavioural disorders $(70.4 \%)$. In total, $84.6 \%$ of the residents received four or more medications (polypharmacy). The mean number of medications used was 6.8 (SD 3.4) per resident.

\section{Main results}

In total, 60 dermatological diseases were diagnosed. The complete list of dermatological findings is shown in the online supplementary table S1. Xerosis cutis was most frequent $(99.1 \%, 95 \%$ CI $97.7 \%$ to $100.0 \%$ ) followed by tinea ungium $(62.3 \%, 95 \%$ CI $56.0 \%$ to $69.1 \%)$ and seborrheic keratosis $(56.5 \%, 95 \%$ CI $50.2 \%$ to $63.0 \%)$. Thirty-two dermatological diseases were diagnosed for five residents or fewer (eg, Bowen's disease, 5/223, allergic contact dermatitis, 2/223, atopic dermatitis $1 / 223)$.

The results of the bivariate associations are shown in table 2. Higher age was associated with the increased prevalence of seborrheic keratosis $(\mathrm{OR}=1.041,95 \%$ CI 1.007 to 1.077) and intertrigo ( $\mathrm{OR}=1.052,95 \% 1.004$ to 1.102$)$. On the other hand, the occurrence of seborrheic dermatitis decreased with increasing age $(\mathrm{OR}=0.951,95 \% \mathrm{CI}$ 0.909 to 0.996 ). Female sex showed a decreased occurrence of androgenetic alopecia (OR $0.187,95 \%$ CI 0.099 to 0.354$)$, tinea pedis $(\mathrm{OR}=0.435,95 \% \mathrm{CI} 0.241$ to 0.786$)$ and actinic keratosis (OR=0.321, 95\% CI 0.165 to 0.622 ). There were statistically significant associations between the Barthel Index and tinea pedis $(\mathrm{OR}=1.013,95 \% \mathrm{CI}$ 1.001 to 1.025$)$ as well as venous insufficiency $(\mathrm{OR}=1.019$, $95 \% \mathrm{CI} 1.005$ to 1.034$)$; and between the duration of residency and tinea ungium $(\mathrm{OR}=0.992,95 \% \mathrm{CI} 0.987$ to $0.998)$ as well as tinea pedis $(\mathrm{OR}=0.987,95 \%$ CI 0.978 to 0.996), but the strength of association were small. Having a university qualification was associated with less occurrence of xerosis cutis $(\mathrm{OR}=0.462,95 \%$ CI 0.175 to 1.223$)$. The number of medications used was associated with the occurrence of venous insufficiency ( $\mathrm{OR}=1.108,95 \% \mathrm{CI}$ 1.011 to 1.214$)$ and scar and fibrosis $(\mathrm{OR}=1.103,95 \% \mathrm{CI}$ 1.000 to 1.217$)$.

Results of the multivariable logistic regression model with tinea pedis as dependent variable is displayed in the online supplementary table S2. Adjusted to the Barthel Index and the duration of residency, the occurrence of tinea pedis was lower in female residents (OR=0.454, 95\% CI 0.245 to 0.893$)$. Results of the multivariable logistic regression model with venous insufficiency as dependent variable is displayed in the online supplementary table S3. The occurrence of venous insufficiency was more likely in residents with higher Barthel Index scores (OR=1.019, 95\% CI 1.004 to 1.033) and higher numbers of drugs ( $\mathrm{OR}=1.110$, 


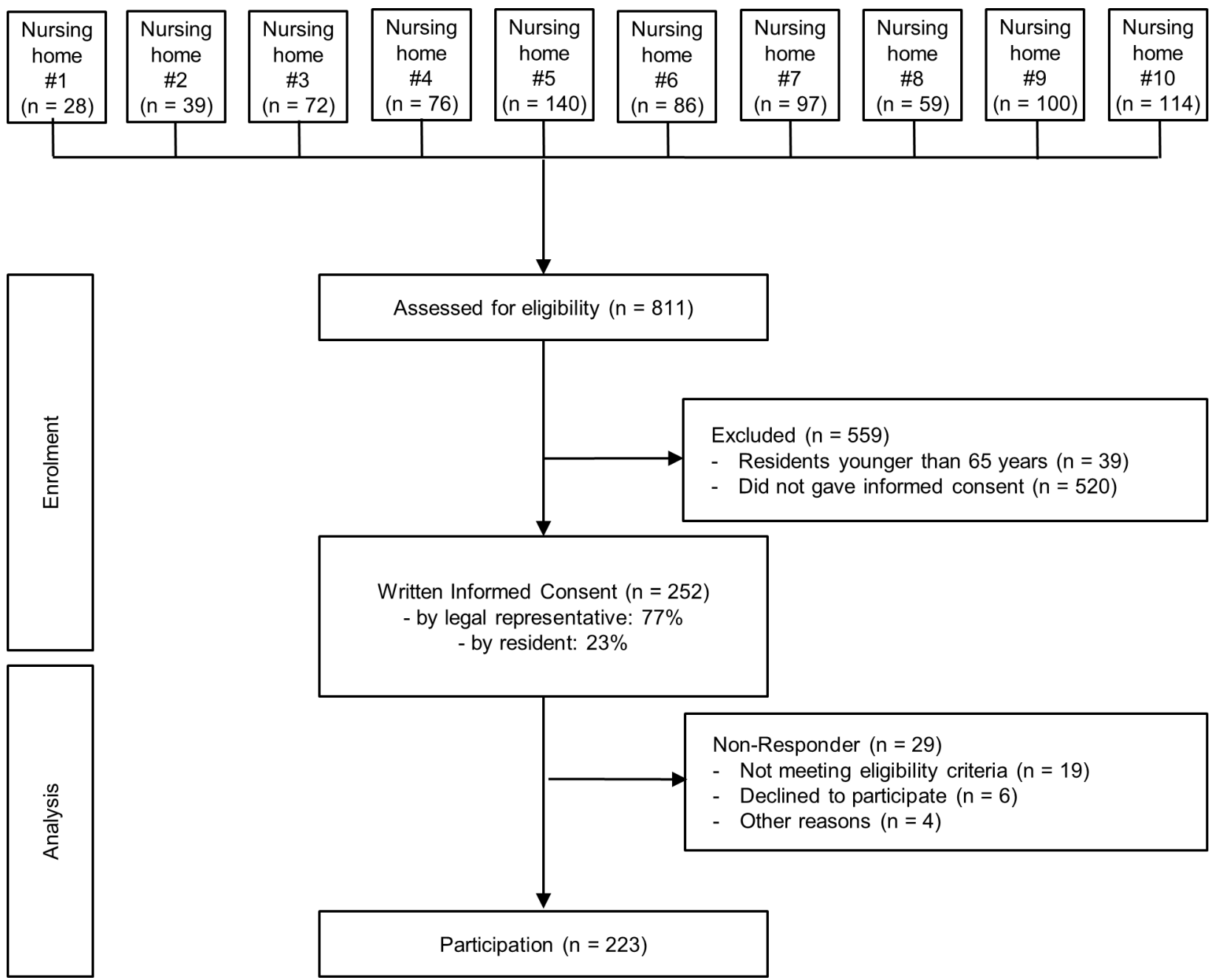

Figure 1 Flow chart of participants.

$95 \%$ CI 1.010 to 1.220$)$. None of the other skin diseases showed multiple associations in the bivariate regression.

\section{DISCUSSION}

\section{Key results}

This prevalence study showed that nearly every resident in institutional long-term care is affected by at least one dermatological disease. In total, 60 dermatological diseases were diagnosed, which was unexpectedly high. The highest prevalence was observed for xerosis cutis followed by tinea unguium, seborrheic keratosis, androgenetic alopecia, IAD and tinea pedis. Only few bivariate associations have been detected between skin diseases and demographic and other characteristics. In the majority, the strengths of associations were small. Male sex was strongly associated with androgenetic alopecia, tinea pedis and actinic keratosis. A university qualification may be protective against xerosis cutis. Increasing age leads to increased risks of seborrheic keratosis and intertrigo and to decreased risks of having seborrheic dermatitis. Overall, the Barthel Index and the duration of residency seem to be unrelated to the occurrence of skin diseases in this population.

\section{Limitations}

Although three additional long-term care facilities were included, the anticipated sample size of $n=280$ was not achieved. In total, $n=559 / 811$ residents living in the institutional long-term care at the time of data collection did not responded, which may had led to a possible selection bias. Even though we performed a randomised selection of all long-term care facilities, there were differences between participating and non-participating institutions. Whether this has an effect on the results is unclear. We also excluded residents at the end of life which may have led to a selection bias. Although we collected numerous data, the systemic diseases were not further specified. This restricts detailed analyses of possible associations. Furthermore, we did not perform laboratory or histology. We also had no control over the documentation quality of the medical records.

\section{Interpretation}

Research in this setting is challenging due to difficulties of gathering written informed consent (eg, due to dementia and associated cognitive impairments) ${ }^{24}$ Irrespectively from that, besides a study published in Turkey in 2007 by Kilic $e t a l,{ }^{25}$ this was the largest randomly selected sample 


\begin{tabular}{|c|c|}
\hline Female, n (\%) & $151(67.7)$ \\
\hline \multicolumn{2}{|l|}{ Age (years) } \\
\hline Mean (SD) & $83.6(8.0)$ \\
\hline Median (IQR) & $84(78-89)$ \\
\hline \multicolumn{2}{|l|}{ Barthel Index total score* } \\
\hline Mean (SD) & $45.1(23.8)$ \\
\hline Median (IQR) & $45.0(25.0-65.0)$ \\
\hline \multicolumn{2}{|l|}{ Braden score* } \\
\hline Mean (SD) & $17.3(3.7)$ \\
\hline Median (IQR) & $18.0(14.0-21.0)$ \\
\hline \multicolumn{2}{|l|}{ BMI $\left(\mathrm{kg} / \mathrm{m}^{2}\right) \dagger$} \\
\hline Mean (SD) & $25.3(5.1)$ \\
\hline Median (IQR) & $24.6(21.9-28.3)$ \\
\hline \multicolumn{2}{|c|}{ Duration of residency (months) } \\
\hline Mean (SD) & $42.6(49.1)$ \\
\hline Median (IQR) & $27.0(14.0-52.0)$ \\
\hline \multicolumn{2}{|c|}{ Highest educational qualification, n (\%) } \\
\hline No school qualification & 3/184 (1.6) \\
\hline Primary school & $34 / 184$ (18.5) \\
\hline Secondary school & 24/184 (10.8) \\
\hline Grammar school/A-level & 7/184 (3.8) \\
\hline Vocational training & 90/184 (48.9) \\
\hline University & $26 / 184(14.1)$ \\
\hline
\end{tabular}

Number of medications per residentł

\begin{tabular}{cc} 
Mean (SD) & $6.84(3.41)$ \\
\hline Median (IQR) & $6.0(4.0-9.0)$ \\
Polypharmacy ( $\geq 4$ medications), n (\%) & $186 / 221$ (84.2)
\end{tabular}

Common concomitant diseases, ICD-10 system level $1, \mathrm{n}$

(\%)

\begin{tabular}{lc}
$\begin{array}{l}\text { Diseases of the circulatory system } \\
\text { (I.00-I.99) }\end{array}$ & $184 / 223(82.5)$ \\
$\begin{array}{l}\text { Mental and behavioural disorders } \\
\text { (F.00-F.99) }\end{array}$ & $157 / 223(70.4)$ \\
$\begin{array}{l}\text { Endocrine, nutritional and } \\
\text { metabolic diseases (E.00-E.99) }\end{array}$ & $122 / 223(54.7)$ \\
$\begin{array}{l}\text { Diseases of the genitourinary } \\
\text { system (N.00-N.99) }\end{array}$ & $106 / 223(47.5)$ \\
$\begin{array}{l}\text { Diseases of the nervous system } \\
\text { (G.00-G.99) }\end{array}$ & $99 / 223(44.4)$ \\
$\begin{array}{l}\text { Diseases of the musculoskeletal } \\
\text { system and connective tissue } \\
\text { (M.00-M.99) }\end{array}$ & $96 / 223(43.0)$ \\
\hline
\end{tabular}

*n, 222; †n, 216; ‡n, 221.

BMI, body mass index; ICD-10, International Coding of Diseases classification.

of residents aged 65 years or older undergoing a headto-toe skin examination by board certified dermatologists in institutional long-term care facilities, compared with previous studies. ${ }^{5} 26$ In our study, prevalence estimates are higher compared with previous studies in this setting, for instance, the prevalence of xerosis cutis, IAD and actinic keratosis. ${ }^{5}{ }^{25}$ 28-30 Otherwise the study of Kilic et al reported a lower prevalence for actinic keratosis, ${ }^{25}$ which may be explained by the geographical region and the assumed darker skin types of examined nursing home residents. Prevalences for tinea pedis, pruritus and candidiasis were similar to previous reports. 2527

The PU prevalence of 9\% was substantially higher compared with previous studies ${ }^{31} 32$ of the German longterm care setting. The main reason for this finding is unclear. Underreporting is a well-known phenomenon in epidemiological PU research. ${ }^{33} 34$ The full head-to-toe skin examination supports the internal validity and the accuracy of this point estimate. This indicates that PUs are a substantial problem in German long-term care settings.

We diagnosed a broad spectrum of dermatological conditions in our study population with a total number of 60 diagnoses, which is unexpectedly high. A study by Makrantonaki et al reported 72 dermatological disorders in a sample of 110 hospitalised elderly patients. ${ }^{35}$ These findings underscore the importance of dermatological examinations in geriatric patients and long-term care residents. However, the prevalence of $>50 \%$ of the reported skin diseases was $2 \%$ or lower. Looking at the clinical spectrum of the diagnosed conditions, a large number are benign, easy to manage or seem to be of minor pathological relevance. Empirical evidence suggests the significant improvement of xerosis cutis in the elderly when using structured skin care regimens. ${ }^{36-40}$ Therefore our data may suggest a possible undersupply. Untreated dry skin is most often related to enhanced pruritus, ${ }^{38}$ and may lead to superficial injuries or wounds with superinfection. ${ }^{41}$ IAD or intertrigo may also be addressed by basic skin care interventions and/or antimycotic therapies. ${ }^{39} 42$ Other diseases like androgenetic alopecia, seborrheic keratosis or pigmentary disorders may be aesthetically disturbing but they do not require imperative medical treatment. However, also psychosocial well-being may be affected possibly leading to restrictions in mental health. ${ }^{41} 43$ Thus, in the elderly and especially in aged long-term care residents, we do have different challenges: realisation of regular dermatological examinations, detecting clinically relevant dermatoses obligatory to be treated, benign skin conditions for facultative treatment and aesthetically disturbing skin conditions with direct implications for physical and psychological well-being.

Some of the conditions identified in our study, like PUs, neoplasm, stasis dermatitis, venous insufficiency or superficial wounds require immediate medical attention. These diseases are frequently observed in this elderly population and may lead to several complications (eg, basal cell carcinoma, ulcus cruris and osteomyelitis) if not treated appropriately. It is important that healthcare practitioners are trained to screen for the most important and significant dermatological conditions in order to path the way for correct and adequate management. 


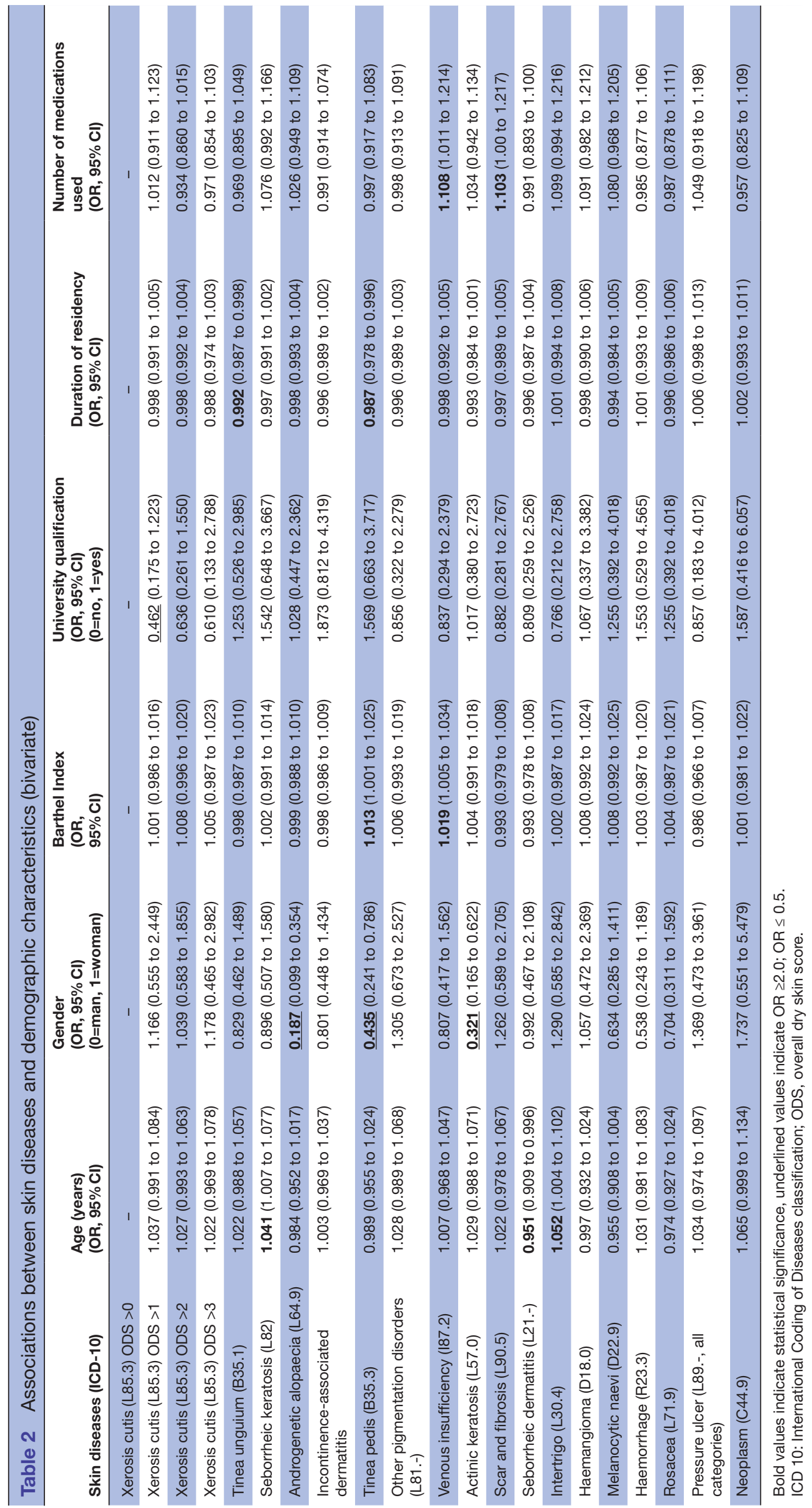


In our study, we also identified conditions which may be considered borderline and may have lower or no importance but others may be simple and frequent conditions with severe consequences if not treated adequately. For instance, tinea pedis is frequent, with frequent relapses and often takes a chronic course. If tinea pedis is not treated properly, it bears the risk to spread to tinea corporis or to lead to onychomycosis and subsequent complications. ${ }^{44}$ The dermatophytes disturb the natural defence of the skin barrier, whereby bacteria and viruses can penetrate into deeper skin layers more easily. The risk of developing lower extremities cellulitis ${ }^{45}$ is increased. Another example of borderline conditions is actinic keratosis, which is a carcinoma in situ with the risk of progressing to squamous cell carcinoma. ${ }^{46}$ The distinction between actinic keratosis and squamous cell carcinoma can be challenging, ${ }^{46}$ but actinic keratosis may progress to a malignant disease. ${ }^{47}$

Interestingly, only few associations between skin diseases and demographic characteristics have been detected. Overall, the presence of skin diseases seems not to be associated with care dependency (Barthel Index) and the duration of residency. This indicates that residents are already affected by the skin disease when being admitted. Apparently they do not develop these conditions de novo in the institutions, but may develop them as a consequence to lifetime exposure to well-known risk factors such as ultraviolet (UV) exposure increasing the risk of skin cancer. ${ }^{48}$ The reason why higher education is associated with less dry skin is unclear. The educational level may be associated with skin self-care behaviour like the regular application of leave-on products.

The association of male sex and androgenetic alopecia was expected, because in the Caucasian population, the prevalence increases with age in men up to $80 \%$ and in women up to $42 \%{ }^{49}$ This may be also associated with actinic keratosis. Because men have a higher prevalence of pattern baldness, there is a reduced natural UV protection on the scalp skin which caused a higher occurrence of actinic keratosis. Also, increased manifestation of tinea pedis in the male gender may possibly be explained to increased hyperhidrosis, lower awareness for skin care (eg, regularly drying between toes, regularly checking feet and inappropriate hygiene habits).$^{50}$

During the last decades, many studies were published reporting the high occurrence of dermatological disorders and the necessity to pay increasing attention to specialised dermatological care in the elderly population. However, is more specialised medical (dermatological) care feasible in this setting and is it cost-effective? A discussion of prioritisation in this vulnerable population is missing so far. Although there is an obvious need of dermatological care in institutional long-term care, it is unlikely that board certified dermatologists will solve this problem. ${ }^{51}$ Telemedicine applications and better medical training of healthcare providers in the institutional longterm care facilities were assumed as being suitable strategies. ${ }^{51}{ }^{52}$ Frequent examinations by a dermatologists, as proposed by others, ${ }^{35} 53$ are unlikely to be affordable and manageable in this setting. Caregivers might be the key because they may have a gatekeeper function. They need to have skills to decide whether residents need medical or basic care and they need to decide when to refer to a specialist. They need to have an evidence-based algorithm for skin care and diagnostic skills to distinguish whether the skin condition is a cosmetic issue, whether it is crucial for skin care, whether it is a borderline disease needing observation or special attention and if it needs urgent medical attention. Therefore, we strongly recommend an algorithm which clarifies the 'who?', 'what?' and 'when' regarding skin care interventions and treatment for nursing and clinical decision making.

\section{Generalisability}

Using a population-based approach, $\mathrm{n}=223$ residents living in institutional long-term care facilities were included. In comparison to the German care statistics, the participating institutional long-term care facilities were more private owned ( $60 \%$ vs $40.8 \%$ in the German care statistic) and there were less non-profit institutions ( $30 \%$ vs $55.8 \%$ in the German care statistic) which may limit the generalisability of results. ${ }^{54}$ Despite a response rate of $27.5 \%$ of residents living in the residential care facilities at time of data collection, demographic data like age, sex and care dependency are well comparable with the general German long-term care population statistics (eg, women $67.7 \%$ vs $72.7 \%$; care-level I: $38.6 \%$ vs $39 \%$; care-level II: $40.8 \%$ vs $40.5 \%$; care-level III: $18.4 \%$ vs $21 \%)^{23}$ which supports the generalisability of the study results. However, a systematic exclusion of for instance highly care depended residents who might also been at higher PU risk may have introduced non-response bias. A response bias due to the informed consent procedure cannot be excluded as well.

Contributors EH: research associate and coordinator of the conducted study, substantial contributions to conception and design and acquisition, analysis and interpretation of data, and preparation of manuscript. UB-P: substantial contributions to conception and design, dermatological examinations, preparation and review of the manuscript. CT: research associate and coordinator of the conducted study, substantial contributions to conception and design, preparation and review of the manuscript. GD: dermatological examinations, medical and scientific advice, and review of the manuscript. IJ: dermatological examinations, medical advice and review of the manuscript. VK: dermatological examinations, medical and scientific advice, and review of the manuscript. CR: review of the manuscript. AL-K: review of the manuscript. NGB: dermatological examinations and review of the manuscript. JK: substantial contributions to conception and design, analysis and interpretation of data, preparation and review of the manuscript.

Funding This investigator initiated clinical study was supported by Galderma Pharma SA (Switzerland) and by the Clinical Research Center for Hair and Skin Science, Department of Dermatology and Allergy, Charité-Universitätsmedizin Berlin. This had no influence on study planning, protocol preparation, study conduct, analyses and reporting.

Competing interests None declared.

Ethics approval Charité-Universitätsmedizin Berlin (EA1/190/14).

Provenance and peer review Not commissioned; externally peer reviewed.

Data sharing statement Additional data of this study is available at clinicaltrials. gov: and the study protocol is published in the International Journal for Nursing 
studies: DOI 10.1016/j.jinurstu.2017.02.006. At the moment there are no plans to share the individual patient data collected.

Open Access This is an Open Access article distributed in accordance with the Creative Commons Attribution Non Commercial (CC BY-NC 4.0) license, which permits others to distribute, remix, adapt, build upon this work non-commercially, and license their derivative works on different terms, provided the original work is properly cited and the use is non-commercial. See: http://creativecommons.org/ licenses/by-nc/4.0/

(c) Article author(s) (or their employer(s) unless otherwise stated in the text of the article) 2017. All rights reserved. No commercial use is permitted unless otherwise expressly granted.

\section{REFERENCES}

1. Cohen-Mansfield J, Jensen B. The preference and importance of bathing, toileting and mouth care habits in older persons. Gerontology 2005;51:375-85.

2. Jafferany M, Huynh TV, Silverman MA, et al. Geriatric dermatoses: a clinical review of skin diseases in an aging population. Int $J$ Dermatol 2012;51:509-22.

3. Diepgen TL. [Demographic changes in Germany. Consequences in health policy and dermatology]. Hautarzt 2003;54:804-8.

4. Jindal R, Jain A, Roy S, et al. Skin disorders among geriatric population at a Tertiary Care Center in Uttarakhand. J Clin Diagn Res 2016;10:WC06-8.

5. Deo MS, Kerse N, Vandal AC, et al. Dermatological disease in the older age group: a cross-sectional study in aged care facilities. BMJ Open 2015;5:e009941.

6. Hay RJ, Fuller LC. Global burden of skin disease in the elderly: a grand challenge to skin health. $G$ Ital Dermatol Venereol 2015;150:693-8.

7. Hahnel E, Lichterfeld A, Blume-Peytavi U, et al. The epidemiology of skin conditions in the aged: a systematic review. J Tissue Viability 2017;26:20-8.

8. Tseng HW, Ger LP, Liang CK, et al. High prevalence of cutaneous manifestations in the elderly with diabetes mellitus: an institutionbased cross-sectional study in Taiwan. J Eur Acad Dermatol Venereol 2015;29:1631-5.

9. Hay RJ, Johns NE, Williams HC, et al. The global burden of skin disease in 2010: an analysis of the prevalence and impact of skin conditions. J Invest Dermatol 2014;134:1527-34.

10. Shah $M$, Coates $M$. An assessment of the quality of life in older patients with skin disease. Br J Dermatol 2006;154:150-3.

11. Kim EK, Kim HO, Park YM, et al. Prevalence and risk factors of depression in geriatric patients with dermatological diseases. Ann Dermatol 2013;25:278-84.

12. Patterson SM, Cadogan CA, Kerse N, et al. Interventions to improve the appropriate use of polypharmacy for older people. Cochrane Database Syst Rev 2014;7:CD008165.

13. Stewart D, Mair A, Wilson M, et al. Guidance to manage inappropriate polypharmacy in older people: systematic review and future developments. Expert Opin Drug Saf 2017;16:203-13.

14. Rollason V, Vogt N. Reduction of polypharmacy in the elderly: a systematic review of the role of the pharmacist. Drugs Aging 2003;20:817-32.

15. Statistisches Bundesamt. Pflegestatistik 2015. Pflege im Rahmen der Pflegeversicherung Ländervergleich - Pflegeheime. Wiesbaden2017.

16. Kottner J, Hahnel E, Trojahn C, et al. A multi-center prevalence study and randomized controlled parallel-group pragmatic trial to compare the effectiveness of standardized skin care regimens on skin health in nursing home residents: a study protocol. Int J Nurs Stud 2015;52:598-604.

17. Junkin J. Targeting incontinence-associated dermatitis. 3rd Congress of the World Union of Wound Healing Societies, 2008.

18. LeBlanc K, Baranoski S, Skin Tear Consensus Panel Members. Skin tears: state of the science: consensus statements for the prevention, prediction, assessment, and treatment of skin tears(c). Advances in skin \& wound care 2011;24:2-15.

19. Serup J. EEMCO guidance for the assessment of dry skin (xerosis) and ichtyosis: clinical scoring systems. Skin Res Technol 1995;1:109-14.

20. Kang BC, Kim YE, Kim YJ, et al. Optimizing EEMCO guidance for the assessment of dry skin (xerosis) for pharmacies. Skin Res Technol 2014;20:87-91.

21. Mahoney FI, Barthel DW. Functional evaluation: the Barthel index. Md State Med J 1965;14:61-5.

22. Ayello EA, Braden B. How and why to do pressure ulcer risk assessment. Adv Skin Wound Care 2002;15:125-31 quiz 132-133.
23. Statistisches Bundesamt. Pflegestatistik 2013. Pflege im Rahmen der Pflegeversicherung Deutschlandergebnisse. Wiesbaden, 2015.

24. Scanlan C. Is anticipated consent an acceptable model for a unique Cohort of research participants? commentary on case study of scabies in nursing homes. Public Health Ethics 2017;10:96-9.

25. Kilic A, Gül U, Aslan E, et al. Dermatological findings in the senior population of nursing homes in Turkey. Arch Gerontol Geriatr 2008;47:93-8.

26. Gunduz T, Gunduz K, Degerli K, et al. Epidemiological profile of Onychomycosis in the elderly living in the nursing homes. Eur Geriatr Med 2014:5:172e4.

27. Nakagami G, Takehara K, Kanazawa T, et al. The prevalence of skin eruptions and mycoses of the buttocks and feet in aged care facility residents: a cross-sectional study. Arch Gerontol Geriatr 2014;58:201-4

28. Lichterfeld A, Lahmann N, Blume-Peytavi U, et al. Dry skin in nursing care receivers: a multi-centre cross-sectional prevalence study in hospitals and nursing homes. Int J Nur Stud 2016;56:37-44.

29. Long MA, Reed LA, Dunning K, et al. Incontinence-associated dermatitis in a long-term acute care facility. $J$ Wound Ostomy Continence Nurs 2012;39:318-27.

30. Zimmaro Bliss D, Zehrer C, Savik K, et al. Incontinence-associated skin damage in nursing home residents: a secondary analysis of a prospective, multicenter study. Ostomy Wound Manage 2006;52:46-55.

31. Hoppe C, Pöhler A, Kottner J, et al. [Pressure ulcers: new data about risk, prevalence and places of development. Results of a study in German nursing homes and hospitals]. Pflege $Z$ 2008;61:90-3.

32. Kottner J, Dassen T, Lahmann N. Prevalence of deep tissue injuries in hospitals and nursing homes: two cross-sectional studies. Int $J$ Nurs Stud 2010;47:665-70.

33. Steingass $\mathrm{S}$, Klein B, Hube G, et al. [New avenues to quality assurance-a model project for recording bedsore incidence]. Gesundheitswesen 2002;64:585-91.

34. Lahmann N, Dassen T, Kottner J. [Frequency of pressure ulcers in german hospitals]. Gesundheitswesen 2012;74:793-7.

35. Makrantonaki E, Steinhagen-Thiessen E, Nieczaj R, et al. Prevalence of skin diseases in hospitalized geriatric patients: association with gender, duration of hospitalization and geriatric assessment. $Z$ Gerontol Geriatr 2016 ; (Epub ahead of print 28 Jun).

36. Brooks J, Cowdell F, Ersser SJ, et al. Skin cleansing and emolliating for older people: a quasi-experimental pilot study. Int J Older People Nurs 2017;12:e12145.

37. Hahnel E, Blume-Peytavi U, Trojahn C, et al. The effectiveness of standardized skin care regimens on skin dryness in nursing home residents: a randomized controlled parallel-group pragmatic trial. Int J Nurs Stud 2017;70:1-10.

38. White-Chu EF, Reddy M. Dry skin in the elderly: complexities of a common problem. Clin Dermatol 2011;29:37-42.

39. Kottner J, Lichterfeld A, Blume-Peytavi U. Maintaining skin integrity in the aged: a systematic review. Br J Dermatol 2013;169:528-42.

40. Shim JH, Park JH, Lee JH, et al. Moisturizers are effective in the treatment of xerosis irrespectively from their particular formulation: results from a prospective, randomized, double-blind controlled trial. J Eur Acad Dermatol Venereol 2016;30:276-81.

41. Blume-Peytavi U, Kottner J, Sterry W, et al. Age-associated skin conditions and diseases: current erspectives and future options. Gerontologist 2016;56(Suppl 2):S230-42.

42. Beeckman D, Van Damme N, Schoonhoven L, et al. Interventions for preventing and treating incontinence-associated dermatitis in adults. Cochrane Database Syst Rev 2016;11:CD011627.

43. Farage MA, Miller KW, Berardesca E, et al. Psychological and social implications of aging skin: normal aging and the effects of cutaneous disease. In: Farage MA, Miller KW, Maibach HI, eds. Textbook of Aging Skin. Berlin, Heidelberg: Springer Berlin Heidelberg, 2014:1-14.

44. Ilkit M, Durdu M. Tinea pedis: the etiology and global epidemiology of a common fungal infection. Crit Rev Microbiol 2015;41:374-88.

45. Al Hasan M, Fitzgerald SM, Saoudian M, et al. Dermatology for the practicing allergist: Tinea pedis and its complications. Clin Mol Allergy 2004;2:5.

46. Röwert-Huber J, Patel MJ, Forschner T, et al. Actinic keratosis is an early in situ squamous cell carcinoma: a proposal for reclassification. Br J Dermatol 2007;156(Suppl 3):8-12.

47. Werner RN, Sammain A, Erdmann R, et al. The natural history of actinic keratosis: a systematic review. Br J Dermatol 2013;169:502-18. 
48. Leiter U, Eigentler T, Garbe C. Epidemiology of skin cancer. Adv Exp Med Biol 2014;810:120-40.

49. Blumeyer A, Tosti A, Messenger A, et al. Evidence-based (S3) guideline for the treatment of androgenetic alopecia in women and in men. J Dtsch Dermatol Ges 2011;9(Suppl 6):S1-57

50. Rossaneis MA, Haddad MC, Mathias TA, et al. Differences in foot self-care and lifestyle between men and women with diabetes mellitus. Rev Lat Am Enfermagem 2016;24:e2761.

51. Lubeek SF, van der Geer ER, van Gelder MM, et al. Current dermatologic care in dutch nursing homes and possible improvements: A Nationwide Survey. J Am Med Dir Assoc 2015:16:e711-716.
52. Lubeek SF, van Gelder MM, van der Geer ER, et al. Skin cancer care in institutionalized elderly in the Netherlands: a nationwide study on the role of nursing home physicians. J Eur Acad Dermatol Venereol 2016;30:e236-e237.

53. Templier C, Boulanger E, Boumbar Y, et al. Systematic skin examination in an acute geriatric unit: skin cancer prevalence. Clin Exp Dermatol 2015;40:356-60.

54. Brüggemann J, Coners E, Gerber H, et al. 4. Pflege-Qualitätsbericht des MDS nach §114A Abs. 6 SGB XI. Qualität in der ambulanten und stationären Pflege. In:Medizinischer Dienst des Spitzenverbandes Bund der Krankenkassen e.V. (MDS), ed.,4. asmuth druck + crossmedia gmbh \& co. kg, Köln, 2014. 